Correspondence

Banur Boynukara

banur61@hotmail.com

Received 26 December 2006

Accepted 27 June 2007

\section{Evolution of slime production by coagulase- negative staphylococci and enterotoxigenic characteristics of Staphylococcus aureus strains isolated from various human clinical specimens}

\author{
Banur Boynukara, ${ }^{1}$ Timur Gulhan, ${ }^{1}$ Kemal Gurturk, ${ }^{1}$ Mustafa Alisarli ${ }^{2}$ \\ and Erdal Ogun ${ }^{3}$ \\ ${ }^{1}$ Department of Microbiology, Faculty of Veterinary Medicine, University of Yuzuncu Yıl, 65080 Van, \\ Turkey \\ ${ }^{2}$ Department of Food Hygiene and Technology, Faculty of Veterinary Medicine, University of \\ Yuzuncu YIl, 65080 Van, Turkey \\ ${ }^{3}$ Department of Biology, Faculty of Arts and Sciences, University of Yuzuncu Yıl, 65080 Van, Turkey
}

\section{INTRODUCTION}

Coagulase-negative staphylococci (CoNS), inhabitants of skin and mucous membranes, are known to be opportunistic pathogens, causing bacterial keratitis and infections in immunocompromised hosts or in patients implanted with medical devices such as intravascular and peritoneal dialysis catheters, prosthetic heart valves and orthopaedic prostheses (Kogan et al., 2006). CoNS are characterized by an ability to colonize the surfaces of biomaterials by adhering in biofilm-structured communities of cells encased in a self-produced polymeric matrix, an amorphous slimy material that is loosely bound to staphylococcal cells. Slime is believed to make the

Abbreviations: CoNS, coagulase-negative staphylococci; SE, staphylococcal enterotoxin. micro-organisms more resistant to administered antibiotics and to host-defence mechanisms (Götz, 2002).

Staphylococcus aureus strains are widespread in nature. They inhabit the skin, mucous membranes, anterior nares, eyes and gastrointestinal tract of asymptomatic individuals, where they can exist as resident or transient members of the normal flora without causing disease. However, some strains are responsible for many nosocomial infections, and in addition are the main causative agent of food intoxication by virtue of their variety of enterotoxins (Stephan et al., 2001).

S. aureus produces a wide variety of toxic proteins, such as toxic shock syndrome toxin 1, exfoliative toxins, and staphylococcal enterotoxins (SEs). In addition to the classical five major antigenic types of SE (SEA, SEB, SEC, SED and SEE), four additional SEs (SEG, SEH, SEI and 
SEJ) have been reported, and their corresponding genes have been described (Rosec \& Gigaud, 2002). In recent times, data resulting from partial or complete genome sequence analyses have led to a rapid expansion of the 'se alphabet' and the description of further 'new' genes (sek, sel, sem, sen, seo, sep, seq, ser and seu) (Letertre et al., 2003).

Recently, many studies have mainly been focused on the slime production of CoNS, but the results of these studies mostly do not reflect the importance of slime-producing CoNS from different clinical sources, including blood, urine and wound samples, and surgical instruments. On the other hand, there is little information on the enterotoxigenic properties of $S$. aureus strains isolated from various human clinical specimens in Turkey or in other countries.

The purpose of the present study was to detect the slime production of CoNS and the enterotoxigenic properties of $S$. aureus strains isolated from various human clinical specimens and to evaluate the importance of the distribution of these pathogens in human clinical specimens.

\section{METHODS}

Source of micro-organisms. The staphylococci tested in this study were isolated from various clinical specimens of patients in the hospital of the University of Yuzuncu Y1l, Van, Turkey, over a period of 6 months. Basic identification of staphylococci was determined by colony morphology, Gram-staining, and catalase and tube coagulase tests (Koneman et al., 1997). Staphylococcus isolates were further identified by the Sceptor bacterial identification system (Becton Dickinson)

Reference strains. The following $S$. aureus reference strains were kindly provided by Dr B. Holmes, National Collection of Type Cultures (NCTC): SEA 10652 FDA 196E, SEB 10654 FDA 243, SEC 10655137 and SED 10656 494. Other reference strains (Staphylococcus epidermidis ATCC 35983, Staphylococcus hominis ATCC 35982) were obtained from our culture collection.

Slime-production test. The ability of CoNS to produce slime was tested as described by Christensen et al. (1982). For the test, four colonies from freshly prepared $5 \%$ sheep blood agar plates were transferred to $10 \mathrm{ml}$ tryptic soy broth (Difco) in $15 \mathrm{ml}$ plastic conical tubes. After incubation for $18-24 \mathrm{~h}$ at $37^{\circ} \mathrm{C}$ under aerobic conditions, the broth was poured gently to examine for the presence of a film on the inside walls of the tubes. The absence of a film or a ring at the liquid-air interface was interpreted as a negative result. Results were evaluated as negative, weak positive $(+1)$, moderately positive $(+2)$ and strongly positive $(+3)$. S. epidermidis ATCC 35983 (tube adherence test positive) and S. hominis ATCC 35982 (tube adherence test negative) were used as control organisms.

Detection of enterotoxins. The enterotoxin types of $S$. aureus strains were determined using the SET-RPLA kit (an SEA, -B, -C and -D detection kit employing reversed passive latex agglutination; Oxoid) following the manufacturer's recommendations. S. aureus strains (SEA 10652 FDA 196E, SEB 10654 FDA 243, SEC 10655137 and SED 10656 494) were used as positive controls; S. epidermidis 33 served as a negative control strain.

\section{RESULTS AND DISCUSSION}

In this study, slime-factor production by CoNS and the enterotoxigenic properties of $S$. aureus strains isolated from various human clinical specimens were determined.

\section{Bacterial isolates}

Out of a total of 120 staphylococci isolated from 280 human clinical specimens of various types, 65 (54.2\%) were identified as CoNS and $55(45.7 \%)$ as S. aureus. The largest number of staphylococci $(44.1 \%)$ were isolated from human blood specimens (Table 1).

\section{Slime production by CoNS}

Thirty-nine (60\%) of CoNS were found to be positive for slime production. Eleven of 39 isolates were found to be weakly positive $(+1), 24$ moderately positive $(+2)$, and four strongly positive $(+3)$ (Table 2). The distribution of the 39 slime-producing CoNS strains by clinical specimen type is presented in Table 3 . Slime production was mostly found in S. hominis (28.2\%) and S. epidermidis (28.2\%). Staphylococcus capitis did not produce slime factor. Blood $(38.5 \%)$, tracheal aspiration $(20.5 \%)$ and urine $(12.8 \%)$ samples were the clinical specimens from which slimeproducing CoNS were most frequently isolated.

Slime production by CoNS isolated from nosocomial bloodstream infections has been observed in 13 of 14 clinical isolates, but in only three of 13 contaminants, and four of 27 skin isolates (Ishak et al., 1985). Kotilainen (1990) reported that the analysis of 64 strains from adult septicaemias disclosed $34(53 \%)$ adherent slime producers, while only $142(29 \%)$ of 489 single blood culture isolates were adherent slime producers. One study showed that 496 isolates $(31 \%)$ from urine samples, 61 (26\%) from catheter tips, and $24(17 \%)$ from cerebrospinal fluid, were slime producers. In another study (Ammendolia et al., 1999), it has been stated that $76.7 \%$ of S. epidermidis produce slime, while the incidence of slime formation is

Table 1. Distribution of CoNS and $S$. aureus by specimen origin

$n$, Number of tested specimens.

\begin{tabular}{|lcccr|}
\hline Origin & $\boldsymbol{n}$ & CoNS (\%) & S. aureus (\%) & Total (\%) \\
\hline Blood & 88 & $33(27.5)$ & $20(16.7)$ & $53(44.1)$ \\
Tracheal aspiration & 47 & $11(9.2)$ & $10(8.3)$ & $21(17.5)$ \\
Urine & 43 & $5(4.2)$ & $9(7.5)$ & $14(11.7)$ \\
Wound/vaginal & 28 & $6(5)$ & $5(4.2)$ & $11(9.2)$ \\
$\quad$ swab & & & & \\
Catheter & 15 & $2(1.7)$ & $3(2.5)$ & $5(4.2)$ \\
Needle & 20 & $2(1.7)$ & $3(2.5)$ & $5(4.2)$ \\
Cerebrospinal fluid & 21 & $2(1.7)$ & $1(0.8)$ & $3(2.5)$ \\
Mixed & 18 & $4(3.3)$ & $4(3.3)$ & $8(6.6)$ \\
Total & 280 & $65(54.2)$ & $55(45.8)$ & $120(100)$ \\
& & & & \\
\hline
\end{tabular}


Table 2. Slime-factor results and titres of CoNS strains

Titres: +1 , weak positive; +2 , moderately positive; +3 , strongly positive.

\begin{tabular}{|lccrrc|}
\hline CoNS & Frequency & No. slime positive (\%) & $\mathbf{+ 1}$ & $\mathbf{+ 2}$ & $\mathbf{+ 3}$ \\
\hline S. hominis & 20 & $11(55)$ & - & 11 & - \\
S. epidermidis & 18 & $11(61.1)$ & 6 & 4 & 1 \\
S. xylosus & 6 & $4(66.7)$ & 2 & 1 & 1 \\
Staphylococcus warneri & 6 & $3(50)$ & 1 & 2 & - \\
S. sciuri & 5 & $3(60)$ & 1 & 2 & - \\
S. haemolyticus & 4 & $3(75)$ & - & 2 & 1 \\
S. simulans & 2 & $2(100)$ & - & 1 & 1 \\
Staphylococcus saprophyticus & 2 & $2(100)$ & 1 & 1 & - \\
S. capitis & 2 & $0(0)$ & - & - & - \\
Total & 65 & $39(60)$ & 11 & 24 & 4 \\
\hline
\end{tabular}

$47.8 \%$ in other CoNS, e.g. Staphylococcus haemolyticus, Staphylococcus xylosus and Staphylococcus simulans. In contrast, another report (Mehrotra et al., 2000) has shown that $58(17.9 \%)$ of CoNS strains are positive for slime production.

Stepanovic et al. (2001) reported that out of 107 (88.4\%) slime-producing Staphylococcus sciuri strains, 26 (24.3\%) were strongly positive and $31(28.9 \%)$ were moderately positive, whereas $50(46.7 \%)$ were weak slime producers. In the present study, two of five S. sciuri strains were found to be moderately positive, and one was weakly positive.

In agreement with our results, Arciola et al. (2002) also reported that $65(57.5 \%)$ of the 113 clinical CoNS isolates were slime-producer strains. Similar studies (Yllmaz et al., 2004; Kogan et al., 2006; Foka et al., 2006) have also shown that the proportion of slime-producing CoNS strains from various human clinical specimens can vary from 20 to $89 \%$. On the other hand, Altoparlak et al. (2004) stated that slime production was mostly detected in CoNS from a patient group $(27.9 \%)$, compared with the CoNS from a control healthy group $(8.7 \%)$.
When our results are compared to those of others, some differences are observed. These variations can be explained by the variation in strain numbers as well as by the assumptions that the Staphylococcus species tested in some studies were isolated under different environmental conditions and that the nature of the strains was different. On the other hand, it should also be considered that slime production may be affected by various factors, such as medium composition, the presence of carbohydrate, iron and $\mathrm{CO}_{2}$, and oxidation (Götz, 2002).

\section{Results of enterotoxigenicity of $\boldsymbol{S}$. aureus}

In the present study, $46(83.6 \%)$ of 55 S. aureus strains were found to be enterotoxigenic. Most $(84.7 \%)$ of the enterotoxigenic $S$. aureus strains were positive for SEA (Table 4).

al Bustan et al. (1996) stated that 115 (86.6\%) of 133 S. aureus isolates from nasal swabs of restaurant workers in Kuwait City produced enterotoxins. They also reported that $33(28.6 \%)$ of enterotoxin-producing strains were positive for SEA, $33(28.6 \%)$ for SEB, 19 (16.4\%) for SEC,

Table 3. Distribution of 39 slime-producing CoNS strains among human clinical specimens

\begin{tabular}{|c|c|c|c|c|c|c|c|c|c|}
\hline \multirow[t]{2}{*}{ CoNS } & \multicolumn{9}{|c|}{ Specimen type: } \\
\hline & $\begin{array}{l}\text { No. positive } \\
\text { strains (\%) }\end{array}$ & Blood & $\begin{array}{c}\text { Tracheal } \\
\text { aspiration }\end{array}$ & Urine & $\begin{array}{c}\text { Wound/ } \\
\text { vaginal swab }\end{array}$ & Catheter & Needle & $\begin{array}{l}\text { Cerebro- } \\
\text { spinal fluid }\end{array}$ & Mixed \\
\hline S. hominis & $11(28.2)$ & 4 & 2 & 2 & 1 & 0 & 1 & 0 & 1 \\
\hline S. epidermidis & $11(28.2)$ & 6 & 0 & 2 & 1 & 0 & 0 & 2 & 0 \\
\hline S. xylosus & $4(10.2)$ & 3 & 1 & 0 & 0 & 0 & 0 & 0 & 0 \\
\hline S. warnerı & $3(7.7)$ & 0 & 3 & 0 & 0 & 0 & 0 & 0 & 0 \\
\hline S. sciuri & $3(7.7)$ & 0 & 0 & 0 & 0 & 1 & 0 & 0 & 2 \\
\hline S. haemolyticus & $3(7.7)$ & 0 & 0 & 1 & 1 & 0 & 0 & 0 & 1 \\
\hline S. simulans & $2(5.1)$ & 1 & 1 & 0 & 0 & 0 & 0 & 0 & 0 \\
\hline S. saprophyticus & $2(5.1)$ & 1 & 1 & 0 & 0 & 0 & 0 & 0 & 0 \\
\hline S. capitis & $0(0)$ & 0 & 0 & 0 & 0 & 0 & 0 & 0 & 0 \\
\hline Total & $39(100)$ & $15(38.5)$ & $8(20.5)$ & $5(12.8)$ & $3(7.7)$ & $1(2.6)$ & $1(2.6)$ & $2(5.1)$ & $4(10.2)$ \\
\hline
\end{tabular}


Table 4. Distribution of enterotoxigenic properties of $S$. aureus strains by specimen origin

\begin{tabular}{|lrrrrrr|}
\hline \multirow{2}{*}{ Sample } & $\begin{array}{c}\text { No. } S . \\
\text { aureus } \\
\text { isolates }\end{array}$ & \multicolumn{4}{c}{ Enterotoxin type } & Total (\%) \\
\cline { 3 - 7 } & & A & B & C & D & \\
\hline Blood & 20 & 12 & 2 & - & 2 & $16(34.8)$ \\
Tracheal aspiration & 10 & 9 & 1 & - & - & $10(21.7)$ \\
Urine & 9 & 8 & - & - & - & $8(17.4)$ \\
Wound/vaginal & 5 & 2 & - & 1 & - & $3(6.5)$ \\
$\quad$ swab & & & & & & \\
Catheter & 3 & 2 & - & 1 & - & $3(6.5)$ \\
Needle & 3 & 3 & - & - & - & $3(6.5)$ \\
Cerebrospinal fluid & 1 & 1 & - & - & - & $1(2.2)$ \\
Mixed & 4 & 2 & - & - & - & $2(4.3)$ \\
Total & 55 & 39 & 3 & 2 & 2 & $46(83.6)$ \\
& & & & & & \\
\hline
\end{tabular}

and four $(3.5 \%)$ for SED, whereas 10 isolates produced both SEA and SEB or SEC. In another study (Becker et al., 1998), of 50 clinical isolates, six (12\%) were positive for SEA, two $(4 \%)$ for SEB and SED, and one (2\%) for SED. Similar results have also been published by Larsen et al. (2000). Fueyo et al. (2001) reported that 32 (29\%) of $S$. aureus strains from human clinical isolates were enterotoxigenic, and of these strains, 14 were positive for SEA, two for SEB, 10 for SEC, two for SED, one for SEA plus SEC, and four for SEC plus SED.

Mehrotra et al. (2000) showed that 37 (34.6\%) of 107 healthy individuals were carriers of enterotoxin-producing S. aureus strains, and determined by PCR that $21(19.6 \%)$ of these strains carried sea, six (5.6\%) seb, eight (7.5\%) sec, and two $(1.9 \%)$ sed.

Hazariwala et al. (2002) found that over $51 \%$ of 41 human $S$. aureus isolates were positive for SE genes by PCR. They also showed by latex agglutination test that $12.2 \%$ of these strains were SEA, $2.4 \%$ SEB, $22 \%$ SEC and $24.4 \%$ SED. Becker et al. (2003) reported that $17(40 \%)$ human $S$. aureus strains were positive by PCR for sea, 10 (2.3\%) for $s e b$, five $(1.2 \%)$ for $s e c$ and three $(0.7 \%)$ for seh genes. Similar results were reported by Letertre et al. (2003).

Boerema et al. (2006) stated that $11(42.3 \%)$ of S. aureus were positive for 'old' se genes (A-E), whereas 21 (80.7\%) were positive for all se genes (A-O). A PCR-based study from Jordan (Naffa et al., 2006) reported that the prevalences of the classic enterotoxin sea, sec, and sea plus sec genes in $S$. aureus isolates from clinical cases were 15, 4 and $4 \%$, respectively.

The conflicting results of our study and those of other investigations concerning the occurrence of enterotoxigenic $S$. aureus isolates from clinical specimens may be due to geographical and methodical variations. Recently, new enterotoxin types (SEG-SEU) have been described (Letertre et al., 2003), but in the current study we could not screen for these enterotoxin types, since the RPLA test kit did not include antisera to detect the new enterotoxins. In addition, $S$. aureus may be able to produce unidentified enterotoxin types that cannot be determined at present (Rosec \& Gigaud, 2002; Boerema et al., 2006). It should also be emphasized that the RPLA method used in this study detects the enterotoxins SEA, SEB, SEC and SED only. Nevertheless, the present study showed a relatively high percentage of enterotoxin-forming $S$. aureus strains from human clinical specimens that seems to be in agreement with the findings of other publications (al Bustan et al., 1996; Fueyo et al., 2001; Hazariwala et al., 2002). In another study we have found that $25.5 \%$ of $S$. aureus strains isolated from subclinical bovine mastitis are enterotoxigenic and that SEA is the predominant enterotoxin type $(23.6 \%)$ detected in these strains (B. Boynukara and others, unpublished data).

In conclusion, SEA is the most frequent enterotoxin type among S. aureus strains from clinical human isolates (Mehrotra et al., 2000; Fueyo et al., 2001; Naffa et al., 2006), and this was confirmed in our study; however, some reports (Hazariwala et al., 2002) have stated that SEC is the predominant enterotoxin type detected in human S. aureus strains.

The results of this study also showed that the incidence of slime formation in CoNS was high in human clinical specimens, and slime production was observed predominantly in CoNS isolated from blood, tracheal aspiration and urine samples. Further studies are necessary for the detection of the new enterotoxin types of S. aureus (SEGSEU) and the corresponding enterotoxin-encoding genes $($ seg-seu).

\section{ACKNOWLEDGEMENTS}

We are thankful to Med. Vet. Mrs Şifa Eşki, employed in the hospital of the University of Yuzuncu Y1l, Van, Turkey, for technical assistance and taking human clinical specimens.

\section{REFERENCES}

al Bustan, M. A., Udo, E. E. \& Chugh, T. D. (1996). Nasal carriage of enterotoxin-producing Staphylococcus aureus among restaurant workers in Kuwait City. Epidemiol Infect 116, 319-322.

Altoparlak, U., Kadanalı, A. \& Çelebi, S. (2004). Slime factor positivity in coagulase negative staphylococci isolated from nasal samples of haemodialysis patients. Int J Clin Pract 58, 1112-1114.

Ammendolia, M. G., Di Rosa, R., Montanaro, L., Arciola, C. R. \& Baldassarri, L. (1999). Slime production and expression of slimeassociated antigen by staphylococcal clinical isolates. J Clin Microbiol 37, 3235-3238.

Arciola, C. R., Campoccia, D., Gamberini, S., Cervellati, M., Donati, E. \& Montanaro, L. (2002). Detection of slime production by means of an optimized Congo red agar plate test based on a colourimetric scale in Staphylococcus epidermidis isolates genotyped for ica locus. Biomaterials 23, 4233-4239.

Becker, K., Roth, R. \& Peters, G. (1998). Rapid and specific detection of toxigenic Staphylococcus aureus: use of two multiplex PCR enzyme 
immunoassays for amplification and hybridization of staphylococcal enterotoxin genes, exfoliative toxin genes, and toxic shock syndrome toxin 1 gene. J Clin Microbiol 36, 2548-2553.

Becker, K., Friedrich, A. W., Lubritz, G., Weilert, M., Peters, G. \& von Eiff, C. (2003). Prevalence of genes encoding pyrogenic toxin superantigens and exfoliative toxins among strains of Staphylococcus aureus isolated from blood and nasal specimens. J Clin Microbiol 41, 1434-1439.

Boerema, J. A., Clemens, R. \& Brightwell, G. (2006). Evaluation of molecular methods to determine enterotoxigenic status and molecular genotype of bovine, ovine, human and food isolates of Staphylococcus aureus. Int J Food Microbiol 107, 192-201.

Christensen, G. D., Simpson, W. A., Bisno, A. L. \& Beachey, E. H. (1982). Adherence of slime-producing strains of Staphylococcus epidermidis to smooth surfaces. Infect Immun 37, 318-326.

Foka, A., Chini, V., Petinaki, E., Kolonitsiou, F., Anastassiou, E. D., Dimitracopoulos, G. \& Spiliopoulou, I. (2006). Clonality of slimeproducing methicillin-resistant coagulase-negative staphylococci disseminated in the neonatal intensive care unit of a university hospital. Clin Microbiol Infect 12, 1230-1233.

Fueyo, J. M., Martin, M. C., Gonzalez-Hevia, M. A. \& Mendoza, M. C. (2001). Enterotoxin production and DNA fingerprinting in Staphylococcus aureus isolated from human and food samples. Relations between genetic types and enterotoxins. Int $J$ Food Microbiol 67, 139-145.

Götz, F. (2002). Staphylococcus and biofilms. Mol Microbiol 43, 1367-1378.

Hazariwala, A., Sanders, Q., Hudson, C. R., Hofacre, C., Thayer, S. G. \& Maurer, J. J. (2002). Distribution of staphylococcal enterotoxin genes among Staphylococcus aureus isolates from poultry and humans with invasive staphylococcal disease. Avian Dis 46, 132-136.

Ishak, M. A., Gröschel, D. H. M., Mandell, G. L. \& Wenzel, R. P. (1985). Association of slime with pathogenicity of coagulase-negative staphylococci causing nosocomial septicemia. J Clin Microbiol 22, 1025-1029.
Kogan, G., Sadovskaya, I., Chaignon, P., Chokr, A. \& Jabbouri, S. (2006). Clinical strains of Staphylococcus that do not contain polysaccharide intercellular adhesin. FEMS Microbiol Lett 255, 11-16.

Koneman, E. W., Allen, S. D., Janda, W. M., Schreckenberger, P. C. \& Winn, W. C. (1997). The Gram-positive cocci, part I: staphylococci. In Color Atlas and Text Book of Diagnostic Microbiology, 5th edn, pp. 511576. Philadelphia, PA: Lippincott.

Kotilainen, P. (1990). Association of coagulase-negative staphylococcal slime production and adherence with the development and outcome of adult septicemias. J Clin Microbiol 28, 2779-2785.

Larsen, H. D., Huda, A., Eriksen, N. H. R. \& Jensen, N. E. (2000). Differences between Danish bovine and human Staphylococcus aureus isolates in possession of superantigens. Vet Microbiol 76, 153-162.

Letertre, C., Perelle, S., Dilasser, F. \& Fach, P. (2003). Detection and genotyping by real-time PCR of the staphylococcal enterotoxin genes sea to sej. Mol Cell Probes 17, 139-147.

Mehrotra, M., Wang, G. \& Johnson, W. M. (2000). Multiplex PCR for detection of genes for Staphylococcus aureus enterotoxins, exfoliative toxins, toxic shock syndrome toxin 1 , and methicillin resistance. J Clin Microbiol 38, 1032-1035.

Naffa, R. G., Bdour, S. M., Migdad, H. M. \& Shehabi, A. A. (2006). Enterotoxicity and genetic variation among clinical Staphylococcus aureus isolates in Jordan. J Med Microbiol 55, 183-187.

Rosec, J. P. \& Gigaud, O. (2002). Staphylococcal enterotoxin genes of classical and new types detected by PCR in France. Int J Food Microbiol 77, 61-70.

Stepanovic, S., Vukovicc, D., Trajkovic, V., Samardzic, T., Cupic, M. \& Svabic-Vlahovic, M. (2001). Possible virulence factors of Staphylococcus sciuri. FEMS Microbiol Lett 199, 47-53.

Stephan, R., Senczek, D. \& Dorigon, V. (2001). Enterotoxin production and other characteristics of Staphylococcus aureus strains isolated from human nasal carriers. Arch Lebensmittelhyg 52, 7-9.

Yılmaz, M., Aral, M. \& Erkman, N. (2004). Determination of slime production by coagulase-negative staphylococci: comparison of two methods. Turk J Infect 18, 53-58. 